\title{
Avaliação química e da atividade antidiarréica das folhas de Byrsonima cinera DC. (Malpighiaceae)
}

\author{
Maria Eloisa Figueiredo', Daniele C. Michelin², Miriam Sannomiya ${ }^{1 *}$, Marcelo A. Silva', \\ Lourdes C. dos Santos ${ }^{1}$, Luis Fernando R. de Almeida ${ }^{3}$, Alba R. M. Souza Brito ${ }^{4}$, \\ Herida R. N. Salgado ${ }^{2}$, Wagner Vilegas ${ }^{1}$
}

\begin{abstract}
1 Instituto de Química, Departamento de Química Orgânica, Unesp - Araraquara, SP, ${ }^{2}$ Departamento de Fármacos e Medicamentos, Faculdade de Ciências Farmacêuticas, Unesp - Araraquara, SP, ${ }^{3}$ Instituto de Biociências, Departamento de Botânica, Unesp - Botucatu, SP, ${ }^{4}$ Departamento de Fisiologia e Biofísica, Instituto de Biologia, Unicamp -Campinas - SP
\end{abstract}

*Correspondência:

M. Sannomiya

Instituto de Química, Departamento de

Química Orgânica, Universidade

Estadual Paulista,

Rua Francisco Degni s/n

14800-900 - Araraquara-SP-Brasil

Email:miriamsannomiya@pop.com.br
Folhas e cascas de algumas especies do gênero Byrsonima (Malpighiaceae) são empregadas popularmente contra diarréia. Contudo, não existem dados na literatura à respeito de investigacões químicas ou farmacológicas dos extratos de B. cinera. Neste estudo, nós avaliamos a atividade antidiarreica dos extratos metanólico e hidrometanólico das folhas de B. cinera em ratos Swiss. Os resultados mostraram que ambos os extratos reduziram signitivamente a motilidade intestinal. Investigacão fitoquímica do extrato metanólico levou ao isolamento e identificacão da (+)catequina e da quercetina-3-O- $\alpha$-L-arabinopiranosídeo. A atividade observada pode estar correlacaionada com a presença dessas substâncias nos extratos.

\section{Unitermos}

- Byrsonima cinera

- Malpighiaceae

- Motilidade intestinal

\section{INTRODUÇÃO}

A região biogeográfica central do Brasil é uma das maiores do mundo (Klink, 1996). Na literatura existem cerca de 6.253 espécies nativas de plantas incluídas em 150-160 famílias na região do cerrado (Mendonça et al., 1998). Muitas plantas pertencentes às mais variadas famílias têm sido empregadas popularmente na região do cerrado no tratamento de diversas doenças, como é o caso das Malpighiaceae (Almeida et al., 1998). A família Malpighiaceae compreende aproximadamente 60 gêneros e 1200 espécies, sendo que 50\% encontram-se no Brasil. Os gêneros mais importantes da América meridional são Malpighia e Byrsonima (Joly, 1977).
Várias espécies pertencentes ao gênero Byrsonima ocorrem no nordeste brasileiro, sendo algumas delas intensamente consumidas na forma de sucos, licores, geléias e doces. De acordo com o NAPRALERT, espécies deste gênero são comumente utilizadas como anti-asmáticas, anti-febris e no tratamento de infecções cutâneas (Caceres et al., 1993).

Até o momento, poucas espécies do gênero Byrsonima foram estudadas quimicamente. Gottlieb et al. (1975) isolaram triterpenos do tronco de B. verbascifolia. As folhas de $B$. microphylla forneceram triterpenos esterificados com ácidos graxos, ácidos triterpênicos, quercetina e galato de metila (Mendes et al., 1999). Vários estudos relatam a química de $B$. crassifolia, da qual 
foram isolados compostos voláteis dos frutos, glicolipídeos, triterpenos, ácidos triterpênicos, catequinas, e flavonóides das folhas (Amarquaye et al., 1994; Rastrelli et al., 1997) e do tronco proantocianidinas e taninos (Geiss et al., 1995). Estudos realizados em nosso grupo de pesquisa mostram o isolamento de amentoflavona, quercetina-3- $O-\beta$-Dgalactopiranosídeo e quercetina-3-O- $\alpha$-L-arabinopiranosídeo das folhas de $B$. crassa (Sannomiya et al., 2004).

Folhas e cascas de algumas espécies de Byrsonima são usadas popularmente em disfunções gástricas, infecções cutâneas, picadas de cobra e ainda como antidiarréicos (Amarquaye et al., 1994). No entanto, não há dados sobre a química ou efeitos farmacológicos de extratos das folhas no sistema gastrintestinal. Tendo em vista a utilização de cascas e folhas de espécies de Byrsonima crassa e B. fagifolia no tratamento de diarréias, este trabalho tem como objetivo a investigação química e antidiarréica de folhas de Byrsonima cinera DC, conhecida popularmente por murici, através do ensaio sobre o trânsito intestinal de camundongos.

\section{MATERIAL E MÉTODOS}

\section{Material vegetal}

O material vegetal, folhas de $B$. cinera, foi coletado e identificado por Campos, C.J (IBB-UNESPBotucatu, SP) em Pratânia-SP. Encontra-se catalogado com o número de exsicata 24163 junto ao herbário da Unesp-Botucatu.

\section{Preparo dos Extratos}

As folhas foram secas e trituradas em moinho de facas e em seguida, foram submetidas às extrações por maceração em $\mathrm{CHCl}_{3}, \mathrm{MeOH}, \mathrm{MeOH} / \mathrm{H}_{2} \mathrm{O}$ 80:20, v/v, respectivamente a partir do mesmo pó. Após a evaporação dos solventes em rotaevaporador foram obtidos $\mathrm{ECHCl}_{3}$ (16,8 g), EMeOH (85,2 g) e EMeOH 80\% (29,6 g).

\section{Fracionamento do extrato metanólico}

$\mathrm{O} \mathrm{EMeOH}$ foi particionado em uma mistura de AcOEt e água $(1: 1, v / v)$. A porção $\operatorname{AcOEt}(4,0 \mathrm{~g})$ foi dissolvida em $15 \mathrm{~mL}$ de $\mathrm{MeOH}$ e submetida à centrifugação. O fracionamento da parte solúvel se deu em coluna de Sephadex LH-20 (57 cm X 3,0 cm d.i.), empregando como eluente $\mathrm{MeOH}$. Obtiveram-se 195 frações, as quais foram reunidas em 17 grupos de frações, após análises cromatográficas por CCD. Consecutivos fracionamentos em CC (sílica-gel) das frações 37 (110 mg) e 43-45 $(160 \mathrm{mg})$ resultaram no isolamento da $(+)$-catequina $(7,0 \mathrm{mg})$ e de quercetina-3- $O-\alpha$-L-arabinopiranosídeo $(16,0 \mathrm{mg})$, respectivamente.

\section{Animais}

Foram utilizados camundongos Swiss (Mus musculus), machos, com 30 dias de idade, pesando entre 22 e $30 \mathrm{~g}$, os quais foram adaptados ao biotério experimental por 5 dias antes do início dos ensaios biológicos. Os animais, com livre acesso à alimentação e à água, foram mantidos em ambiente com temperatura de $20 \pm 1^{\circ} \mathrm{C}$, umidade monitorada e fotoperíodo de 12 horas claro/escuro. No dia do experimento, os animais foram mantidos em jejum por 3 horas e recebendo água ad libitum.

\section{Teste da motilidade intestinal em camundongos}

No ensaio de trânsito intestinal foram utilizados $\mathrm{EMeOH}$ e EMeOH 80\%, ressuspendidos em solução fisiológica a $50 \mathrm{mg} / \mathrm{mL}$.

Foram constituídos 3 grupos experimentais com 10 animais cada, sendo que 2 grupos foram tratados com o extrato vegetal $(1000 \mathrm{mg} / \mathrm{kg})$, e um com solução fisiológica $(10 \mathrm{~mL} / \mathrm{kg})$, controle, os quais receberam as soluções por via oral através de gavage.

Após 45 minutos, os animais receberam a suspensão de carvão ativo $10 \%$ em solução de goma arábica 5\%, 0,5 $\mathrm{mL} /$ animal, também através de gavage.

Após 45 minutos, os camundongos foram sacrificados em câmara de $\mathrm{CO}_{2}$ e foi realizada a extirpação imediata do intestino desde o piloro até o início do ceco. Assim, foi feita a medida do comprimento total do intestino delgado e da distância percorrida pela suspensão de carvão ativo. $\mathrm{O}$ resultado foi expresso em porcentagem do comprimento total do intestino delgado.

A atividade sobre o trânsito intestinal foi determinada segundo Janssen \& Jageneau (1957) e Wong \& Wai (1981).

Esta pesquisa foi aprovada pelo Comitê de Ética em Pesquisa da Faculdade de Ciências Farmacêuticas da Unesp - Araraquara através do parecer n ${ }^{\circ}$ 09/2004.

\section{Análise estatística}

A análise estatística foi realizada utilizando-se o teste $t$ de Student's - não pareado. Foi utilizado o nível de significância estatística de $\mathrm{P}<0.05$. A análise estatística foi realizada de acordo com a metodologia preconizada para o ensaio sobre o trânsito gastrintestinal no qual se 
TABELA I - Porcentagem da distância percorrida pelo carvão ativo no intestino dos camundongos após a administração dos extratos EMeOH e EMeOH 80\% das folhas de Byrsonima cinera

\begin{tabular}{lcc}
\hline Tratamento & $\begin{array}{c}\text { Dose } \\
\text { (mg/kg de peso animal) }\end{array}$ & $\begin{array}{c}\text { Distância percorrida pelo carvão } \\
\text { ativo (\%) } \pm \text { desvio padrão }\end{array}$ \\
\hline Controle & $10 \mathrm{~mL} / \mathrm{kg}$ & $75,63 \pm 12,26$ \\
$\mathrm{EMeOH}$ & $1000 \mathrm{mg} / \mathrm{kg}$ & $65,99 \pm 9,14^{*}$ \\
$\mathrm{EMeOH} 80 \%$ & $1000 \mathrm{mg} / \mathrm{kg}$ & $68,27 \pm 14,42^{*}$ \\
\hline
\end{tabular}

$\mathrm{n}=10 ; \%=$ média dos 10 animais; $* P<0,05$

compara dois grupos, segundo Rouf et al. (2003) e Bafna \& Bodhankar (2003).

\section{RESULTADOS E DISCUSSÃO}

O fracionamento da porção acetato de etila do extrato metanólico das folhas de $B$. cinera resultou, até o momento, no isolamento da $(+)$-catequina e quercetina-3$O-\alpha$-L-arabinopiranosídeo os quais foram identificados através da comparação dos dados espectroscópicos com os da literatura (Harborne, 1993; Agrawal, 1989).

As análises cromatográficas dos extratos polares de B. cinera por CCD revelados em NP/PEG e solução de anisaldeído/ácido sulfúrico também mostraram a similaridade existente dos constituintes químicos entre os extratos, devido à presença de catequinas e flavonóides nos mesmos.

Estes resultados corroboram com estudos já realizados com outras espécies de Byrsonima, onde foram também detectadas essas mesmas classes de metabólitos secundários (Amarquaye et al., 1994; Rastrelli et al., 1997; Sannomiya et al., 2004).

O ensaio do trânsito intestinal em camundongos demonstrou significativa redução da motilidade intestinal dos animais após administração dos extratos metanólico e hidrometanólico de $B$. cinera, quando comparados com o controle (Tabela I).

De acordo com a literatura, alguns flavonóides apresentam atividade antidiarréica como no caso da quercetrina, quercetina e ternatina. Essa atividade dos flavonóides foi observada através de experimentos de diarréia crônica em ratos e motilidade do trânsito intestinal de camundongos (Galvez et al., 1993; Galvez et al., 1996; Rao et al., 1997).

Os dados obtidos com B. cinera mostram-se relevantes, já que não há dados sobre a química ou efeitos farmacológicos de extratos das folhas no sistema gastrintestinal desta espécie na literatura. Esta atividade observada pode estar relacionada com a presença de catequinas e flavonóides nos extratos polares de $B$. cinera
(Rao et al., 1997; Galvez et al., 1991; Galvez et al., 1993; Galvez et al., 1996).

\section{CONCLUSÕES}

A avaliação da atividade anti-diarréica em camundongos dos extratos metanólico e hidrometanólico das folhas de $B$. cinera apresentou uma redução significativa da motilidade intestinal no modelo experimental adotado.

$\mathrm{O}$ estudo químico da fração AcOEt do extrato metanólico resultou no isolamento de $(+)$-catequina e quercetina-3-O-a-L-arabinopiranosídeo. A atividade observada pode estar relacionada com a presença destas classes dos compostos isolados. Outros estudos serão realizados para avaliar a atividade dos compostos isolados, bem como o mecanismo de ação envolvido.

\section{ABSTRACT \\ Chemical evaluation and antidiarrhoeal activity of leaves of Byrsonima cinera DC. (Malpighiaceae)}

Leaves and bark of some Byrsonima species (Malpighiaceae) are popularly employed against diarrhoeal diseases. However, no data were reported in the literature about the chemisty and pharmacology of extracts from B. cinera leaves. In the present study we evaluated the anti-diarrhoeal activity of methanolic and hydromethanolic extracts obtained from the leaves of $\mathrm{B}$. cinera in Swiss mice. Results showed that both extracts reduced significantly the gastrintestinal motility. Phytochemical evaluation of the methanolic extract led to the isolation and identification of $(+)$-catechin and quercetin-3-O- $\alpha-\mathrm{L}-$ arabinopyranoside. The observed activity may be correlated to the presence of these compounds in the extract.

UNITERMS: Byrsonima cinera. Malpighiaceae. Intestinal motility 


\section{AGRADECIMENTOS}

À FAPESP pela bolsa concedida à Figueiredo M. E. e Sannomiya M., e ao CNPq para Michelin D. C.

\section{REFERÊNCIAS BIBLIOGRÁFICAS}

ALMEIDA, S. P.; PROENÇA, C. E. B.; SANO, S. M.; RIBEIRO, J. F. Cerrado: espécies vegetais úteis: 38-9, Planaltina:EMBRAPA, 1998. 465p.

AGRAWAL, P. K. Carbon 13 NMR of flavonoids. Amsterdam: Elsevier, 1989. 564 p.

AMARQUAYE, A.; CHE, C. T.; BEJAR, E.; MALONE, M. H.; FONG, H. H. S. Anew glycolipid from Byrsonima crassifolia. Planta Med., v. 60, n. 1, p. 85-86, 1994.

BAFNA, P., BODHANKAR. S. Gastrointestinal effects of Mebarid ${ }^{\circledR}$, an ayurvedic formulation, in experimental animals. J. Ethnopharmacol., v. 86 p. 173-176, 2003.

CACERES, A.; FIGUEROA, L.; TARACENA, A. M.; SAMAYOA, B. Plants used in guatemala for the treatment of respiratory-diseases .2. Evaluation of activity of 16 plants against gram-positive bacteria. $J$. Ethnopharmacol., v. 39, n. 1, p. 77-82, 1993.

GALVEZ, J.; CRESPO, M. E.; JIMENEZ, J.; SUAREZ, A.; ZARZUELO, A. Antidiarrheic activity of quercitrin in mice and rats. J. Pharm. Pharmacol., v. 45, n. 2, p. 157159, 1993.

GALVEZ, J.; DUARTE, J.; DEMEDINA, F. S.; JIMENEZ, J.; ZARZUELO, A. Inhibitory effects of quercetin on guinea-pig ileum contractions. Phyto. Res., v. 10, n. 1, p. 66-69, 1996.

GALVEZ, J.; ZARZUELO, A.; CRESPO, M. E.; UTRILLA, M. P.; JIMENEZ, J.; SPIESSENS, C.; DEWITTE, P. Antidiarrheic activity of Sclerocaryabirrea bark extract and its active tannin constituent in rats. Phyto. Res., v. 5, n. 6, p. 276-278, 1991.

GEISS, F.; HEINRICH, M.; HUNKLER, D.; RIMPLER, H.; HEINRICH, M. Proanthocyanidins with (+)epicatechin units from Byrsonima crassifolia bark. Phytochemistry, v. 39, n.3, p. 635-643, 1995.
GOTTLIEB, O. R.; HENRIQUES MENDES, P.; TAVEIRA MAGALHÃES, M. Triterpenoids from Byrsonima verbascifolia. Phytochemistry, v. 14, n. 5-6, p. 1456-1456, 1975.

HARBORNE, J. B. The flavonoids: advances in research since 1986. New York : Chapman \& Hall, 1993. 676 p.

JANSSEN, P. A. J.; JAGENAU, A. H. Anew series of potent analgesics. Part I - Chemical Structure and Pharmacological Activity. J. Pharm. Pharmacol., v. 9, n. 6, p. 381-400, 1957.

JOLY, A. B. Botânica - Introdução à taxonomia vegetal. 4 ed. São Paulo: Cia Editora Nacional, 1977. 777p.

KLINK, C. A. Relação entre o desenvolvimento agrícola e a biodiversidade. In: INTERNATIONAL SYMPOSIUM ON TROPICAL SAVANNAS, $1^{\text {st }}, 1996$, Brasília. Proceedings...Brasília: [s.n.], 1996. p. 25-27.

MARTINEZ-VASQUEZ, M.; GONZALEZ-ESQUINCA, A. R.; CAZARES LUNA, L.; MORENO GUTIÉRREZ, M. N.; GARCÍA-ARGÁEZ, A. N. Antimicrobial activity of Byrsonima crassifolia (L.) H.B.K. J. Ethnopharmacol., v. 66, n. 1, p. 79-82, 1999.

MENDES, C. C.; CRUZ, F. G.; DAVID, J. M.; NASCIMENTO, I. P.; DAVID, J. P. Triterpenes esterified with fatty acid and triterpene acids isolated from Byrsonima microphylla. Quim. Nova, v. 22, n. 2, p. 185$188,1999$.

MENDONÇA, R. C.; FELFILI, J. M.; WALTER, B. M. T.; SILVA, M. C.; REZENDE, A. R.; FILGUIERAS, T. S.; NOGUEIRA, P. E. Flora vascular do Cerrado. In: SANO, S. M, ALMEIDA, S. P., (Eds.). Cerrado ambiente e flora. Brasília: EMBRAPA, 1998. p. 286-556.

RAO, V. S. N.; SANTOS, F. A.; SOBREIRA, T. T.; SOUZA, M. F.; MELO, C. L.; SILVEIRA, E. R. Investigations on the gastroprotective and antidiarrhoeal properties of ternatin, a tetramethoxyflavone from Egletes viscose. Planta Méd., v. 63, n. 2, p. 146-149, 1997.

RASTRELLI, L.; DETOMMASI, N.; BERGER, I.; CACERES, A.; SARAVIA, A.; DE SIMONE, F. Glycolipids from Byrsonima crassifolia. Phytochemistry, v. 45, n. 4, 647-650, 1997. 
ROUF, A. S. S.; ISLAM, M. S.; RAHMAN, M. T. Evaluation of antidiarrhoeal activity Rumex maritimus root. J. Ethnopharmacol. v. 84, p. 307-310, 2003.

SANNOMIYA, M.; RODRIGUES, C. M.; COELHO, R. G.; SANTOS, L. C.; HIRUMA-LIMA, C. A.; SOUZABRITO, A. R. M.; VILEGAS, W. Application of preparative high-speed counter-current chromatography for the separation of flavonoids from the leaves of Byrsonima crassa Niedenzu (IK). J. Chromatogr. A, v. 1035, n. 1, p. 47-51, 2004.
WONG, C. L.; WAY, M. K. Effects of aspirin and paracetamol on naloxone reversal or morphine-induced inhibition of gastrointestinal propulsion in mice. Eur. $J$. Pharmacol., v.73, n. 1, p. 11-19, 1981.

Recebido para publicação em 23 de julho de 2004. Aceito para publicação em 08 de outubro de 2004. 
O arquivo disponível sofreu correções conforme ERRATA publicada no Volume 41 Número 2 da revista. 